\title{
Evaluation of Lignins of Trunk and Roots from Citrus sinensis L. Osbeck: A Large Available Brazilian Biomass
}

\author{
Deyvid S. Porto, ${ }^{a}$ Moacir R. Forim, ${ }^{\circledR *, a}$ Eveline S. Costa, ${ }^{a}{ }^{\text {João B. Fernandes }}{ }^{a}$ and \\ Maria F. G. F. da Silva ${ }^{\circledR a}$ \\ ${ }^{a}$ Laboratório de Produtos Naturais, Departamento de Química, Universidade Federal de São Carlos, \\ Rod. Washington Luiz, km 235, 13565-905 São Carlos-SP, Brazil
}

\begin{abstract}
Citrus biomass is a source of biobased products and presents extensive chemical diversity. Among the structural macromolecules, lignins have been used in resins, bioplastics, and nanoencapsulation. Brazil has a large source of lignins, which are orange trees removed from groves that need to be renewed. However, the knowledge about these lignins is limited and little explored. Thus, this work aimed to evaluate the lignins from Citrus sinensis and to provide information on the interesting use of orange trees as a source of macromolecules. The lignins were isolated from the trunk, central and secondary roots from the orange tree by Technical Association of the Pulp and Paper Industry (TAPPI)-methods. The lignin contents for the extractive-free samples were $19.8 \pm 0.19,21.9 \pm 0.36$, and $19.5 \pm 0.41 \%(\mathrm{~m} / \mathrm{m})$ in the trunk, central and secondary roots, respectively. Infrared (IR) and ${ }^{13} \mathrm{C}$ nuclear magnetic resonance (NMR) analyses confirmed typical bands and chemical shifts to syringyl and guaiacyl units. These results are consistent with the features of lignins previously reported for orange tree branches and hardwood roots. The greatest amount of lignin in the orange tree was found in the central root. The lignins extractive-free by TAPPI-T264 cm-97 presented low solubility in organic solvents, due to their compaction and folding, which was confirmed by ${ }^{13} \mathrm{C} \mathrm{NMR}$ in the solid-state, differential scanning calorimetry (DSC) and thermogravimetric analysis (TGA).
\end{abstract}

Keywords: lignocellulosic biomass, trunk and roots orange biomass, lignin extraction, lignin characterization, solubility, Brazilian citrus waste

\section{Introduction}

Reusing and valuing available biomass resources are approaches that have gained increasing attention from governments and industries. The search for the use of renewable resources and the development of new technology, able to add value to the products, has led to an increase in the use of lignocellulosic biomass products to produce such as biofuels, biomaterials, and biochemicals to replace equivalent compounds obtained from non-renewed petroleum sources. ${ }^{1-4}$

That approach for the biomass conversion into valueadded products involves a system named biorefinery. The biorefinery concept still considers the production of energy and addresses all articulated production around to the agroindustrial complex of several crops. ${ }^{3,5,6}$

Citrus sp. is one of the crops of the largest global production, resulting in about 15-25 million tons of biomass

*e-mail: mrforim@ufscar.br annually that is derived from fruit and juice production. ${ }^{7}$ The Citrus genus includes tangerines, grapes, lemons, limes, and oranges, which are widely known and marketed worldwide. ${ }^{89}$ Citrus sinensis (popularly known as orange) has been one of the leading horticultural products in Brazil, which is the world leader in orange production with approximately 15 million tons in the 2019/2020 harvest. ${ }^{10}$ São Paulo and west-southwest Minas Gerais citrus belt are responsible for more than $80 \%$ of orange production in Brazil, ${ }_{11}^{11}$ with almost 370,000 hectares of plantation and more than 174 million bearing trees in 2019. However, there is an eradicated and abandoned grove area of 17,728 hectares with 7.4 million orange trees lost between 2019 and 2020, approximately. ${ }^{12}$ This total represents almost a million tons of orange tree wood lost every year.

Several biomasses, such as sugarcane and sisal, have been used for the production of biofuels and bioproducts, ${ }^{13,14}$ however, orange tree biomass has still been used only for energy generation by combustion. ${ }^{15,16}$ The juice and orange fruits production systems result in the generation 
of different biomasses such as bagasse and management wood (trunk, central and secondary roots), as well as residues such as yellow water rich in flavonoids (Figure 1). Oranges have diverse components of industrial interest such as flavonoids, minerals, essential oils (terpenes), amino acids, proteins, hemicellulose, pectins, cellulose and lignins that should be better studied and applied. For instance, their bagasse may be applied in the production of pellets, $d$-limonene, commercial pectin, and as adsorbent material. Moreover, it is possible to obtain cellulose and lignins from previously pruned orange trees. ${ }^{17-19}$

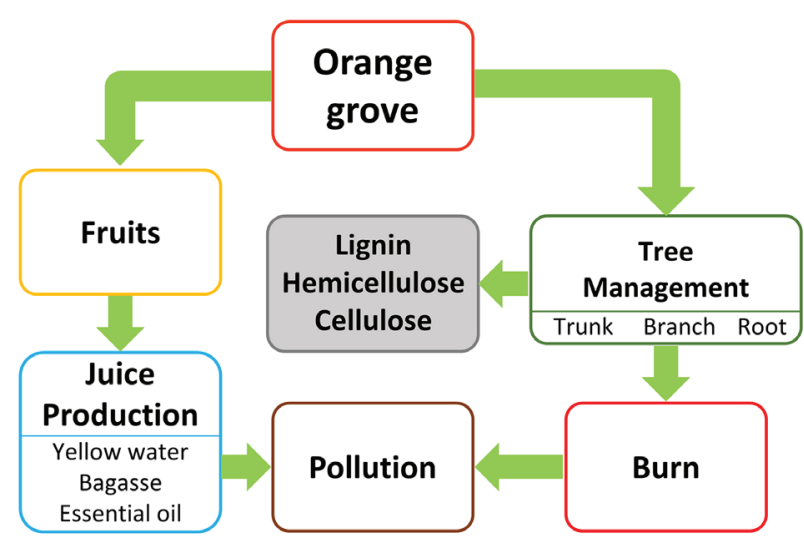

Figure 1. Production of fruits and orange juice, and their generated sub products in the chain production.

Lignins (from the Latin lignum, meaning wood) is a non-carbohydrate aromatic macromolecule, mainly composed of the precursors $p$-coumaryl, coniferyl and sinapyl alcohols (Figure 2), which differ by the presence or absence of methoxy groups in the ortho position of the aromatic skeleton. ${ }^{20,21}$ Lignin production is currently linked to three main pulping processes, called sulfite, kraft, and soda. The majority of the industrial lignin is obtained by kraft and sulfite processes, which produce the so-called lignosulfonates. Although large quantities of lignins are burned in the energy production, their application in the different productive sector have been

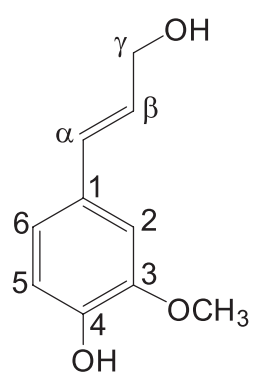

(I)

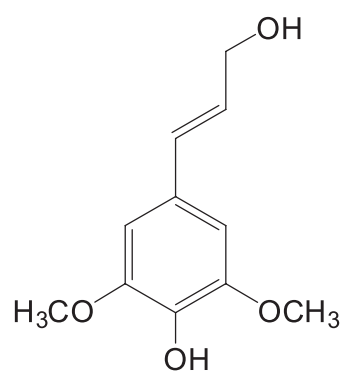

(II)

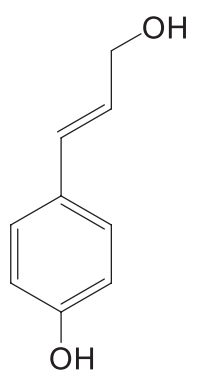

(III)
Figure 2. Lignin precursors: coniferyl (I), sinapyl (II), and p-coumaryl (III) alcohols. outstanding such as dispersant in concrete, pigments, ceramic products, emulsifier to oils and latex, pellet binder, lignopolyurethanes, vanillin production, antioxidants, etc. $^{22-25}$

In this study, the potential of orange trees obtained after their management was evaluated to verify the lignin content in the trunk, central and secondary roots using the Klason process, the characterization, and thermal features. The Klason method ${ }^{26,27}$ is consolidated in the quantification of lignin for its reproducibility, repeatability, and it is easily applied to any type of wood. Moreover, extractive, holocellulose, ash, and moisture contents were evaluated using Technical Association of the Pulp and Paper Industry (TAPPI) ${ }^{27-29}$ and other standard methods for these types of analyses in Brazil (ISO ${ }^{30}$ and Embrapa). ${ }^{31}$ Due to the large availability of biomass from Citrus sinensis trees (an environmental problem for the industry) and the absence of information, especially for the use of their roots and trunks in the biomolecules productions, this study may help in the development of materials from orange waste lignins.

\section{Experimental}

The trunk (Tr) (above the graft port), central root (CR) and secondary root (SR) of C. sinensis were obtained from an orange tree plantation from Agroterenas S.A. Citrus, in the western part of the São Paulo State, Brazil, during the management of trees of 22-years old. A part of the trunk with approximately $20 \mathrm{~cm}$ of diameter from one tree and central and secondary roots from another tree were collected. The wood matrices were washed in running water, dried in a circulating air oven at $40{ }^{\circ} \mathrm{C}$ for 9 days, and triturated to 60 mesh standards.

Different parts of the orange tree were characterized by determination of their ash, holocellulose, standard, and acetone extractives according to the standard methods ISO 3451-1:2008, ${ }^{30}$ Embrapa document $236,{ }^{31}$ TAPPI T264 cm-97, ${ }^{28}$ and TAPPI T280 pm-99, ${ }^{29}$ respectively. The extractives using TAPPI T280 pm-99 were also evaluated with a green solvent method and for the evaluation of the quantification of lignin in relation to TAPPI T264 cm-97. The moisture content was calculated by thermogravimetric analyzer (Shimadzu TGA-50 Thermobalance), using $0.5 \mathrm{~g}$ of sample with heating at $105{ }^{\circ} \mathrm{C}$ for the time required until the measured mass stabilizes.

\section{Determination of lignin content and extraction}

The lignin was quantified in the trunk, central and secondary roots by determination of acid-insoluble lignin 
according to TAPPI T222 om- $02 .{ }^{27}$ Klason method was performed using $1.0 \mathrm{~g}$ of extractive-free orange tree samples by TAPPI T264 cm-97 and T280 pm-99, dried in an air circulation oven at $60{ }^{\circ} \mathrm{C}$, in $15 \mathrm{~mL}$ of $72 \% \mathrm{H}_{2} \mathrm{SO}_{4}$ (sulfuric acid). The mixture was stirred and macerated for $2 \mathrm{~h}$, and then diluted with $3 \%(\mathrm{v} / \mathrm{v}) \mathrm{H}_{2} \mathrm{SO}_{4}$ aqueous solution. Afterward, the system was heated at $110{ }^{\circ} \mathrm{C}$ for $4 \mathrm{~h}$ and filtered. The lignin remaining soluble in the 3\% $\mathrm{H}_{2} \mathrm{SO}_{4}$ aqueous solution after filtration was determined in $205 \mathrm{~nm}$ with UV spectrophotometer (PerkinElmer Lambdar 35), as described at TAPPI T222 om-02. Elemental analysis was performed for samples extractivefree by TAPPI T264 cm-97 and for trunk extractive-free by TAPPI T280 pm-99, using $1.0 \mathrm{mg}$ of the samples previously dried at $60{ }^{\circ} \mathrm{C}$ for $48 \mathrm{~h}$, and an elemental analyzer (CE Instruments).

\section{Infrared spectroscopy with Fourier transform}

Infrared spectroscopy with Fourier transform (FTIR) analyses were performed on the FTIR spectrometer (Shimadzu Tracer-100). The spectra were obtained using $1.0 \mathrm{mg}$ of samples and $100 \mathrm{mg}$ of potassium bromide $(\mathrm{KBr})$, processed in pellets. The spectra were obtained at a resolution of $4 \mathrm{~cm}^{-1}, 32$ scans ranging from 4000 to $450 \mathrm{~cm}^{-1}$.

The FTIR spectra could be used to calculate the guaiacyl $(\mathrm{G})$ and syringyl (S) ratio $(\mathrm{S} / \mathrm{G})$, according to Kline et al. ${ }^{32}$ The intensity of bands at 1327 and $1267 \mathrm{~cm}^{-1}$, assigned to guaiacyl (G) and syringyl (S) units, respectively, were used to quantitative evaluation of $S / G$ ratio from absorbance found in the obtained spectra from the process described above.

\section{Solid-state nuclear magnetic resonance}

Solid-state nuclear magnetic resonance (SS-NMR) experiments were performed using a Bruker Avance III spectrometer $(9.4 \mathrm{~T})$ operating at $100.57 \mathrm{MHz}$ for ${ }^{13} \mathrm{C}$, employing a CP/MAS (cross polarization/magic angle spinning) probe equipped with $4 \mathrm{~mm}$ spinners and $100 \mathrm{mg}$ of each sample. The spectra were recorded using a spin-rate of $5 \mathrm{kHz}, 4096 \mathrm{scans}$, an acquisition time of $0.034 \mathrm{~s}$, and time domain size (TD) of 32k.

The content of alkyl- $O$-aryl bonds ( $\alpha-O-4$ and $\beta-O-4)$ in phenyl-propane units (PPU) was determined in the NMR spectra. According to Evstigneyev et al. ${ }^{33}$ the chemical shift range at $96-68$ ppm corresponds to alkyl- $O$-aryl bond, and it can be correlated with typical signals for aromatic carbons around $162-102 \mathrm{ppm}$ finding the alkyl- $O$-aryl content in PPU, in accordance with the equation 1:
Alkyl-O-aryl (n / 100 PPU) $=2.22+\frac{\mathrm{I} 96-68}{\mathrm{I} 162-102} \times 100$

where $\mathrm{n}$ is the number of alkyl- $O$-aryl bonds and I is the integration in the range of chemical shifts detailed.

The methoxyl groups content was determined using the integration of the chemical shift range at $58-54 \mathrm{ppm}$ and by the typical signals for aromatic carbons at 162-102 ppm on the ${ }^{13} \mathrm{C}$ NMR spectra, as described by Evstigneyev et al., ${ }^{33}$ according to the equation 2 :

$\mathrm{OMe}(\%)=0.74\left(\frac{\mathrm{I} 58-54}{\mathrm{I} 162-102} \times 100\right)+3.8$

\section{Differential scanning calorimetry}

The thermal features of the lignins extracted was evaluated by differential scanning calorimetry (DSC, PerkinElmer 8000) using $8.0 \mathrm{mg}$ of the samples of lignins from the trunk, central, and secondary roots, extractivefree by T264 cm-97 and T280 pm-99, using an aluminum crucible as container. The temperature ranged from 25 to $170{ }^{\circ} \mathrm{C}$, with a heating and cooling rate of $20^{\circ} \mathrm{C} \mathrm{min}^{-1}$, using $\mathrm{N}_{2}$ in a flow rate of $50 \mathrm{~mL} \mathrm{~min}{ }^{-1}$.

The DSC analyses for lignins and extractive-free samples were performed in two cycles. The first heating was performed to erase the thermal history of the samples. The thermal history is related to the heating and cooling processes in which the sample was submitted before the thermal analysis, allowing to verify if there are solvents residues and moisture.

\section{Thermogravimetric analysis}

The thermogravimetric analysis (TGA) was performed in a PerkinElmer Pyris I, using $8.0 \mathrm{mg}$ of lignin samples from the trunk, central and secondary roots, extractive-free by T264 cm- 97 and T 280 pm-99 by using platinum support. The temperature ranged from 25 to $900^{\circ} \mathrm{C}$, heating rate of

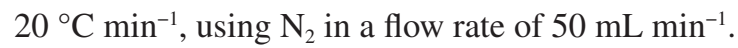

\section{Results and Discussion}

\section{Biomass characterization}

The results for the different parts of the orange tree obtained by determination of moisture, ashes, holocellulose, extractives standard (TAPPI T264 cm-97), and extractives acetone (TAPPI T280 pm-99) are presented in Table 1.

The trunk and the secondary roots presented similar levels of moisture (showing themselves a relative standard 
Table 1. Composition of the trunk, central and secondary roots from the orange tree

\begin{tabular}{|c|c|c|c|}
\hline & Trunk / \% (m/m) & Central root / \% (m/m) & Secondary root $/ \%(\mathrm{~m} / \mathrm{m})$ \\
\hline Moisture & $7.9 \pm 0.12$ & $6.8 \pm 0.08$ & $7.5 \pm 0.15$ \\
\hline Ash & $2.8 \pm 0.12$ & $8.2 \pm 0.05$ & $5.5 \pm 0.18$ \\
\hline Holocellulose $^{\mathrm{a}}$ & $68.6 \pm 0.10$ & $69.0 \pm 0.09$ & $65.7 \pm 0.04$ \\
\hline Holocellulose ${ }^{b}$ & $74.6 \pm 0.38$ & $74.3 \pm 0.12$ & $67.4 \pm 0.99$ \\
\hline Extractive $^{\mathrm{a}}$ & $12.1 \pm 0.41$ & $12.2 \pm 0.40$ & $13.6 \pm 1.03$ \\
\hline Extractive $^{b}$ & $6.3 \pm 0.13$ & $7.3 \pm 0.31$ & $9.9 \pm 0.06$ \\
\hline
\end{tabular}

axtractive-free by TAPPI T264 cm-97; bextractive-free by TAPPI 280 pm-99.

deviation (RSD) of $3.5 \%$ ), and significantly different to the central root, with RSD of $9.1 \%$. Both the trunk and secondary roots are directly linked to conducting water in the plant structure, the secondary root is mainly responsible for water absorption. However, the central root may have lower water levels due to its supporting structural function. The ash content may be explained due to the different functions that each cell structure or part of the plant present in the dynamics of the plant organism. The higher levels of ash found in the samples of central and secondary roots can be due to the presence of organs/vessels responsible for the absorption of the minerals from the soil. ${ }^{34}$

The extraction by TAPPI T264 cm-97 starts with the removal of nonpolar substances (using toluene/ethanol) as the waxes and fats, followed by extraction of compounds of medium polarity (using ethanol) such as flavonoids. Finally, the last extraction, polar (water), provides compounds such as sugars and glycosides..$^{35}$ The extraction was efficient to obtain all fractions from nonpolar to polar extractives, due to its wide polarity variation among toluene, ethanol, and water. This explains the lower value of extractives found in acetone by TAPPI T280 pm-99 since this solvent is able to extract only substances such as non-volatile fatty acids, resins, sterols, waxes, and hydrocarbons. ${ }^{35}$ According to Gomes et al. ${ }^{35}$ the extraction using acetone is advised to quantify the extractives that are relevant for the cellulosic pulping due to its low cost and lower environmental impact than toluene extraction.
The holocellulose contents presented an average of $70.0 \pm 4.6 \%(\mathrm{~m} / \mathrm{m})$ and values close to described for lignocellulosic materials of hardwood, $71.7 \pm 5.7 \%(\mathrm{~m} / \mathrm{m}){ }^{36,37}$ However, holocellulose contents for samples extractive-free by TAPPI T280 pm-99 were higher than those obtained for samples extractive-free by TAPPI T264 $\mathrm{cm}-97$, probably due to the presence of contaminants such as compounds of medium polarity (e.g., flavonoids). The lowest extractive value for the TAPPI T280 pm-99 samples generated a decrease in holocellulose content, presenting a false-positive result.

\section{Quantification and structural analysis of lignin}

The analytical characteristics of the lignins in the trunk, central, and secondary roots extractive-free by TAPPI T264 cm-97 (standard), and T280 pm-99 are presented in Table 2.

The percentage of lignin extractive-free by TAPPI T264 cm-97 in the trunk (19.8\%), central (21.9\%) and secondary roots $(19.5 \%)$ samples presented values in accordance with the lignin contents often found in lignocellulosic biomass. ${ }^{37,38}$ The percentage of lignin obtained in the trunk was close to that described ${ }^{17,39}$ for branches of orange trees, approximately $20 \%(\mathrm{~m} / \mathrm{m})$, value found in branches with diameters around $1.0 \mathrm{~cm}$. Here we used orange tree trunk with approximately $20 \mathrm{~cm}$ of diameter and 22-years old. The plant age, the organ used,

Table 2. Lignin content and contents of functional groups, bonds and units of lignin in the trunk, central and secondary roots samples from the orange tree

\begin{tabular}{|c|c|c|c|c|c|c|}
\hline Lignin & $\begin{array}{l}\text { Acid-insoluble } \\
\text { lignin / \% (m/m) }\end{array}$ & $\begin{array}{c}\text { Acid-soluble } \\
\text { lignin / \% (m/m) }\end{array}$ & $\begin{array}{c}\text { Total lignin / } \\
\%(\mathrm{~m} / \mathrm{m})\end{array}$ & $\mathrm{S} / \mathrm{G}$ ratio & $\mathrm{OMe} / \%$ & $\begin{array}{l}\text { Alkyl- } O \text {-aryl bond / } \\
(\mathrm{n} / 100 \mathrm{PPU})^{\mathrm{a}}\end{array}$ \\
\hline Trunk $^{b}$ & $19.6 \pm 0.19$ & $0.17 \pm 0.01$ & $19.8 \pm 0.19$ & 1.006 & 17.12 & 53.28 \\
\hline Central root ${ }^{\mathrm{b}}$ & $21.7 \pm 0.39$ & $0.20 \pm 0.01$ & $21.9 \pm 0.36$ & 1.007 & 16.13 & 55.50 \\
\hline Secondary root ${ }^{b}$ & $19.3 \pm 0.41$ & $0.21 \pm 0.03$ & $19.5 \pm 0.41$ & 0.992 & 16.67 & 57.91 \\
\hline Trunk $^{\mathrm{c}}$ & $22.2 \pm 0.18$ & $0.18 \pm 0.06$ & $22.4 \pm 0.17$ & 1.012 & 16.72 & 49.33 \\
\hline Central root ${ }^{\mathrm{c}}$ & $21.2 \pm 0.03$ & $0.17 \pm 0.02$ & $21.4 \pm 0.01$ & 1.029 & 15.55 & 52.86 \\
\hline Secondary $\operatorname{root}^{\mathrm{c}}$ & $22.3 \pm 0.10$ & $0.16 \pm 0.02$ & $22.4 \pm 0.11$ & 0.997 & 15.93 & 50.95 \\
\hline
\end{tabular}

aPPU: phenyl-propane units; bextractive-free by TAPPI T264 cm-97; ' extractive-free by TAPPI T280 pm-99. S: syringyl; G: guaiacyl. 
soil, climate, and other factors are important in the wood constitution, and they may change the percentages of the macromolecules found in Citrus sinensis. As a result of these abiotic factors, it is often inappropriate to compare studies carried out with the same species from different ages or origins. ${ }^{36}$ At the central and secondary roots, the found percentage of lignin was similar to described by González et al. ${ }^{39}$ for orange pruning samples $(20 \%, \mathrm{~m} / \mathrm{m})$. According to Zhang et al., ${ }^{40}$ the Populus (hardwood) and Pinus (softwood) genus present 19 and $28 \%$ of lignins in their roots, respectively. ${ }^{40}$ The amount of lignin found in the Citrus sinensis roots was similar to reported for roots of the genus Populus, being suitable for wood contents of Angiosperms. The absence of previous studies of lignins from orange roots did not allow the comparison of the content obtained in this study with other works involving the same species. This paper is the first report that describes the lignin content in roots and trunk of Citrus sinensis.

The results for the lignins content obtained by extractive-free TAPPI T280 pm-99 were higher than those found by extractive-free TAPPI T264 cm-97 protocol. This difference can be explained by the lower extraction efficiency with only acetone and water, solvents of medium and high polarity, as previously described for extractives.

Samples of lignins from the trunk, central and secondary roots, extractive-free by TAPPI T264 cm-97 method, will still be used in the discussion of FTIR and NMR characterization analyses, as well as lignins of the trunk extractive-free by TAPPI T280 pm-99. The remaining samples were not detailed since they present similar data, which would be redundant.

The results of the elemental analysis carbon lignins of the trunk, central and secondary roots, extractive-free by TAPPI T264 cm-97, and trunk, extractive-free by TAPPI T280 pm-99, ranged between 59 and 60\%. This result is close to that found for syringyl (57.9\%) and guaiacyl $(60.9 \%)$ units, described in hardwood. ${ }^{41}$ The data of the elemental analysis can be found in the Supplementary Information (SI section, Table S1).

\section{Lignin solubility}

Samples of lignins of the different organs from the orange tree presented low solubility in dimethyl sulfoxide (DMSO, Millipore, Bedford, MA, USA), which was used for ${ }^{1} \mathrm{H}$ and ${ }^{13} \mathrm{C}$ NMR analysis. The solubility assay was carried out to solvents commonly used for lignin solubilization. Ethyl acetate, methanol, tetrahydrofuran (THF), dichloromethane (J. T. Baker, Ecatepec, Mexico), acetone, chloroform, pyridine (Synth, São Paulo, Brazil), dimethylformamide (DMF, Panreac, Barcelona, Spain), and DMSO were used..$^{42}$ For this assay, the lignin obtained from the orange tree trunk (extractive-free by TAPPI T264 cm-97) was used in different solvents (Figure 3).

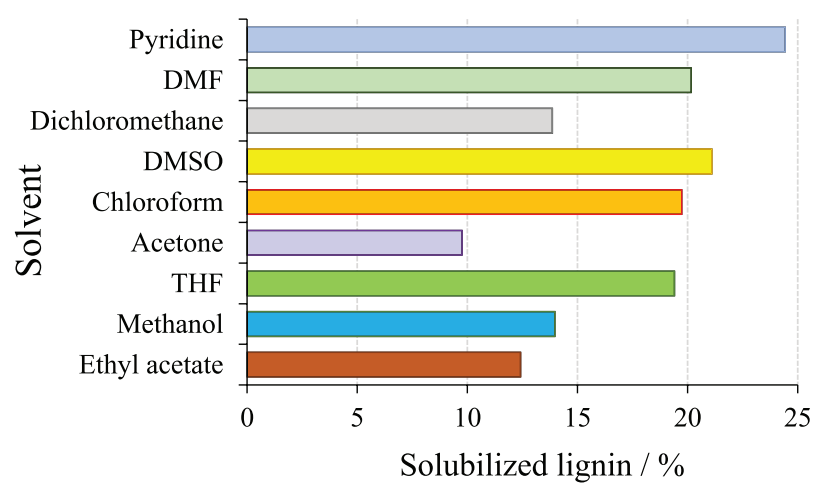

Figure 3. Percentage of extractive-free lignin of trunk obtained by TAPPI T264 cm-97, solubilized in different solvents at $25^{\circ} \mathrm{C}$.

Pyridine presented the best solubilization efficiency, followed by DMSO, DMF, chloroform, and THF. Despite this, pyridine was effective to solubilize only $24.0 \pm 0.4 \%$ of total lignin, in a ratio of $2 \mathrm{~g} \mathrm{~L}^{-1}$.

Due to the low solubility of the extractive-free to lignin, it was not possible to carry out the analysis by size exclusion chromatography (SEC) and NMR in solution. ${ }^{31} \mathrm{P}$ NMR analysis to quantitatively determine hydroxyl groups in lignin ${ }^{43}$ was performed to the extractive-free obtained by the TAPPI T264 cm-97 method from the orange trunk samples. However, the lignin was not fully derivatized due to its low solubility. Due to the same reason, the 2D NMR analysis (HSQC: heteronuclear single quantum coherence spectroscopy) was not performed.

\section{Infrared spectroscopy}

The bands commonly found in the lignin infrared analysis are related to the olefin group in the propyl chain, the aromatic rings, as well as to the ethers, esters, aldehydes, ketones, and alcohols moieties. Table 3 shows the main IR absorption bands found to lignins in this study. The assignments of the bands were reported according to data found in the literature. ${ }^{44,45}$

The FTIR spectra are shown in Figure 4. The samples extractive-free presented the typical bands of lignins as described in Table $3 .^{38,41,44}$ All the lignins presented bands at $1,300 \mathrm{~cm}^{-1}$, characteristic of $\mathrm{C}-\mathrm{O}$ stretching of the syringyl structure, and at $1,110 \mathrm{~cm}^{-1}$, corresponding to the carbon $\mathrm{C}-\mathrm{H}$ of the syringyl units. The stretching of the $\mathrm{C}-\mathrm{O}$ bonds at $1,267 \mathrm{~cm}^{-1}$ is typical of the guaiacyl units. Stretching at $1,025 \mathrm{~cm}^{-1}$ of $\mathrm{C}-\mathrm{O}(\mathrm{H})$ and $\mathrm{C}-\mathrm{O}(\mathrm{C})$ bonds confirm the ether and hydroxyl groups present in the syringyl and guaiacyl units. According to Ibrahim et al. ${ }^{44}$ 
Table 3. FTIR absorption bands and assignments for Klason lignins

\begin{tabular}{|c|c|}
\hline Band $/ \mathrm{cm}^{-1}$ & Assignment \\
\hline $3,400-3,405$ & $\mathrm{O}-\mathrm{H}$ stretching (phenolic $\mathrm{OH}$ and aliphatic $\mathrm{OH}$ ) \\
\hline $2,925-2,960$ & $\mathrm{C}-\mathrm{H}$ stretching $\left(\mathrm{CH}_{3}\right.$ and $\mathrm{CH}_{2}$ groups $)$ \\
\hline $2,840-2,850$ & $\mathrm{C}-\mathrm{H}$ stretching $\left(\mathrm{OCH}_{3}\right)$ \\
\hline ca. 1,600 & $\mathrm{C}-\mathrm{C}$ stretching (aromatic skeleton) \\
\hline 1,513 & $\mathrm{C}-\mathrm{C}$ stretching (aromatic skeleton) \\
\hline 1,460 & $\mathrm{C}-\mathrm{H}$ deformation (asymmetric in $-\mathrm{CH}_{3}$ and $-\mathrm{CH}_{2}$ ) \\
\hline 1,425 & $\begin{array}{c}\mathrm{C}-\mathrm{C} \text { stretching (aromatic skeleton) with } \mathrm{C}-\mathrm{H} \text { in-plane } \\
\text { deformation }\end{array}$ \\
\hline 1,327 & $\mathrm{C}-\mathrm{O}$ stretching (syringyl) \\
\hline 1,267 & $\mathrm{C}-\mathrm{O}$ stretching (guaiacyl) \\
\hline ca. 1,220 & $\begin{array}{c}\mathrm{C}-\mathrm{O}(\mathrm{H}) \text { and } \mathrm{C}-\mathrm{O}(\mathrm{Ar}) \text { stretching (phenolic } \mathrm{OH} \text { and } \\
\text { ether in guaiacyl) }\end{array}$ \\
\hline 1,115 & $\mathrm{Ar}-\mathrm{CH}$ in plane deformation (syringyl) \\
\hline ca. 1,030 & $\begin{array}{c}\mathrm{C}-\mathrm{O}(\mathrm{H}) \text { and } \mathrm{C}-\mathrm{O}(\mathrm{C}) \text { (first order aliphatic } \mathrm{OH} \text { and } \\
\text { ether) }\end{array}$ \\
\hline 915 & $\mathrm{C}-\mathrm{H}$ out of plane (aromatic ring) \\
\hline
\end{tabular}

these signals confirm syringyl and guaiacyl units together with the other $\mathrm{O}-\mathrm{H}$ stretching (phenolic and aliphatic) at $3,400 \mathrm{~cm}^{-1}, \mathrm{C}-\mathrm{H}$ stretching $\left(\mathrm{CH}_{3}\right.$ and $\left.\mathrm{CH}_{2}\right)$ at $2,930 \mathrm{~cm}^{-1}$ and $\mathrm{C}-\mathrm{C}$ (aromatic skeleton) at $1,610 \mathrm{~cm}^{-1}$. The infrared spectrum confirmed that the lignins of Citrus sinensis have similarities to hardwood type, characterized by the presence of guaiacyl and syringyl units. ${ }^{41}$

The FTIR spectra for lignin samples of the trunk, central and secondary root extractive-free by TAPPI T280 pm-99 method, are shown in Figure S1 (SI section).

The calculation of guaiacyl and syringyl ratio $(\mathrm{S} / \mathrm{G})$ has been employed from the quantitative measurement of absorbance bands in FTIR. ${ }^{32,46}$ The bands at 1,327 to $1,267 \mathrm{~cm}^{-1}$ correspond to the $\mathrm{C}-\mathrm{O}$ stretching of $\mathrm{S}$ and $\mathrm{G}$ units, respectively, and the ratio of the absorbance values correspond to the $\mathrm{S} / \mathrm{G}$ ratio. As noted in Table 2, the lignins extraction-free by the T264 cm-97 presented similar $\mathrm{S} / \mathrm{G}$ ratio (approximately 1 ) and were close to found for hardwood lignins, in a $\mathrm{S} / \mathrm{G}$ ratio of $0.957 .{ }^{32}$

\section{Solid-state nuclear magnetic resonance}

NMR analyses in solution are often employed to soluble lignins obtained from processes such as kraft and $\operatorname{soda}^{45}$ to identify functional groups, information about the aromatic substituents in the units composing the lignins, type of connections, etc. ${ }^{47}$ However, in many cases, there are problems about the lignin analysis due to its solubility, resulting in difficulties to its characterization. At the same time, the solid-state ${ }^{13} \mathrm{C}$ NMR spectroscopy has been used to insoluble materials. ${ }^{48}$ Considering the low solubility of lignin, the solid-state NMR approach was used for the analyses of lignins obtained by TAPPI T264 cm-97 and T280 pm-99 methods.

The main chemical shifts observed to the lignin structure were related to aromatic carbons, oxidized, and aliphatic carbons as described in Table 4. The assignments of the bands were reported according to data found in the literature..$^{20,49-53}$ The NMR spectra for lignins of the trunk, central and secondary roots extractive-free by TAPPI T264 cm-97 method, and lignin of trunk (TrAC) extractive-free by TAPPI T280 pm-99 method, are shown in Figure 5.

Through the analysis of NMR spectra, it was possible to verify similarities among the lignins from the different
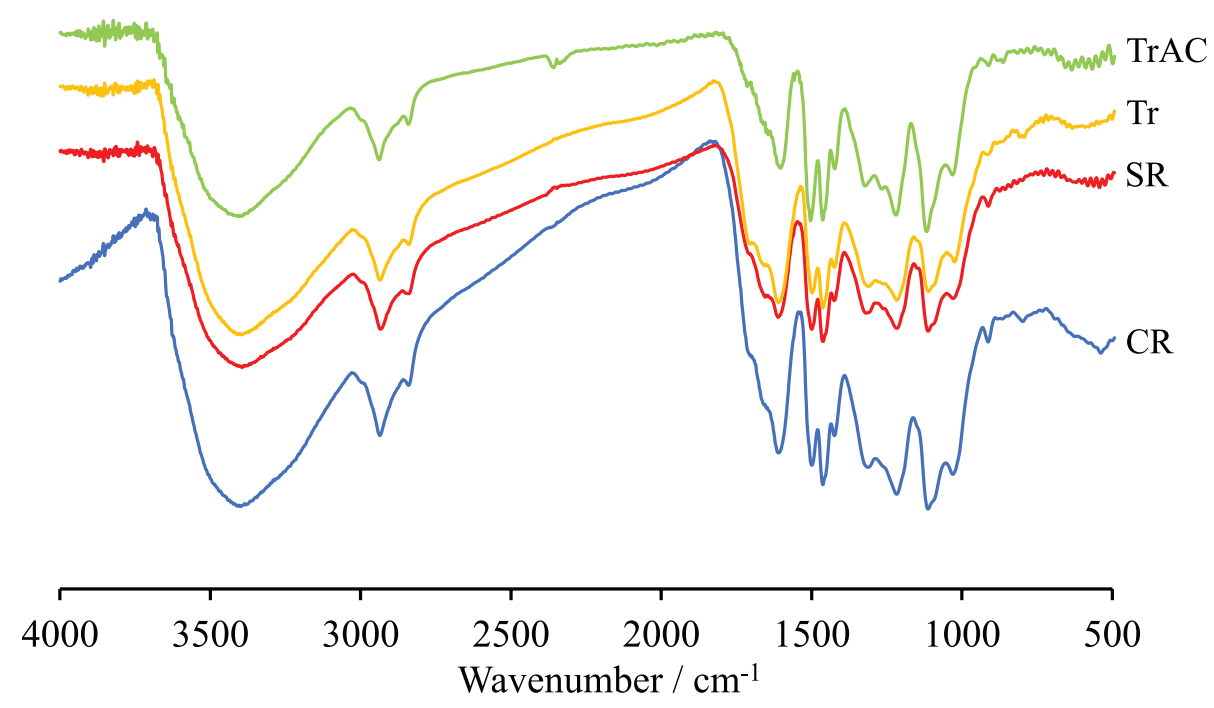

Figure 4. FTIR (KBr) spectra for lignins from the trunk (Tr), central (CR), and secondary (SR) roots extractive-free by TAPPI T264 cm-97 method, and of the trunk (TrAC) extractive-free by TAPPI T280 pm-99 method (AC = acetone). 
Table 4. NMR chemical shifts for lignin commonly found in wood

\begin{tabular}{lc}
\hline Assignment & $\begin{array}{c}\text { Chemical } \\
\text { shift / ppm }\end{array}$ \\
\hline $\mathrm{C}_{\alpha}$ with carbonyl groups $(\mathrm{C}=\mathrm{O})$ & 174 \\
$-\mathrm{COO} / \mathrm{CH}_{3} \mathrm{COO}$ of hemicellulose & 173 \\
$\mathrm{C}_{3}$ and $\mathrm{C}_{5}$ to $\mathrm{S}$ units etherified $(\mathrm{C}-\mathrm{O})$ & 153 \\
$\mathrm{C}_{4}$ to $\mathrm{G}$ units etherified $(\mathrm{C}-\mathrm{O})$ & $148-146$ \\
$\mathrm{C}_{3}$ and $\mathrm{C}_{4}$ not etherified & $148-146$ \\
$\mathrm{C}_{1}$ to $\mathrm{G}$ and $\mathrm{S}$ units etherified and not etherified & $137-131$ \\
$\mathrm{C}_{6}$ to $\mathrm{G}$ units & 120 \\
$\mathrm{C}_{5}$ to $\mathrm{G}$ units & 115 \\
$\mathrm{C}_{2}$ to $\mathrm{G}$ units $(\mathrm{C}-\mathrm{H})$ & 112 \\
$\mathrm{C}_{\alpha}$ with $\alpha$ - $O$-ether in $\beta-\beta$ & \\
$\mathrm{C}_{\beta}-\mathrm{OR}$ & $86-82$ \\
$\mathrm{C}_{\alpha}$-OH to $\mathrm{C}_{\beta}$ with $\beta-O-4$ & 73 \\
$\mathrm{C}_{\gamma}-\mathrm{OH}$ & $64-60$ \\
$-{ }_{-} \mathrm{OCH}$ & $57-55$ \\
$\mathrm{C}_{3}$-aliphatic groups not bonded to oxygenated groups & $52-15$ \\
$\mathrm{C}_{\alpha}, \mathrm{C}_{\beta}$ unsaturated $(\mathrm{C}=\mathrm{C})$ & $31-29$ \\
$\mathrm{CH}_{3}$ of hemicellulose & 21.6 \\
\hline
\end{tabular}

S: syringyl; G: guaiacyl.

orange tree parts and extraction methods. The spectra showed the presence of the chemical shift at $30 \mathrm{ppm}$, which refers to the $\alpha$ and $\beta$ carbons of methylene groups (not bonded to oxygenated groups) in the propanoid chain (Figure 2). The presence of methoxyl group $\left(-\mathrm{OCH}_{3}\right)$ was observed through the signals between 55 and $57 \mathrm{ppm},{ }^{20}$ and the of $\mathrm{C}_{\gamma}-\mathrm{OH}$ by chemical shift at $60 \mathrm{ppm}$. The lignin samples presented a signal at $73 \mathrm{ppm}$, related to $\mathrm{C}_{\gamma}-\mathrm{OH}$ with $\mathrm{C}_{\beta}$-bonding of $\beta-O-4$ type ${ }^{53}$ The aromatic skeleton could be confirmed by chemical shifts ranging from 110 to $170 \mathrm{ppm}$. In all spectra, we observed signals between 110-115 ppm related to $\mathrm{C}_{2}$ and $\mathrm{C}_{5}$ of the guaiacyl units, as well as at $133 \mathrm{ppm}$ described for the $\mathrm{C}_{1}$ of guaiacyl and syringyl units. The chemical shifts for $\mathrm{C}_{3}$ and $\mathrm{C}_{4}$ from guaiacyl and $\mathrm{C}_{3}$ and $\mathrm{C}_{5}$ from syringyl units could be observed at $148 \mathrm{ppm}$. This chemical shift is often used to identify the carbons of the guaiacyl units. The signal at $153 \mathrm{ppm}$ is related for $\mathrm{C}_{3}$ and $\mathrm{C}_{5}$ of syringyl etherified units. ${ }^{49}$

The absence or low intensity of chemical shifts between 90 and 102 ppm suggests a low concentration, or lack of residual sugars, similar to what happens to hemicellulose with chemical shifts around 170-175 ppm, but not observed at $20 \mathrm{ppm} .{ }^{51,52}$ The chemical shift at $174 \mathrm{ppm}$ observed in all spectra indicates a $\mathrm{C}_{\alpha}$ with carbonyl groups. ${ }^{49} \mathrm{In}$ lignin obtained by Klason process, it is common to find up to $5 \%$ of residual carbohydrates. The infrared data are also consistent with the results obtained by SS-NMR, confirming the presence of the guaiacyl and syringyl units..$^{51}$ The NMR spectra for lignins of central and secondary roots extractive-free by TAPPI T280 pm-99 are shown in Figure S2 (SI section).

The results for the alkyl- $O$-aryl content in the different lignins are shown in Table 2. The different lignins extractive-free by TAPPI T264 cm-97 presented similar alkyl- $O$-aryl content (average of $55.56 \pm 2.35 / 100 \mathrm{PPU}$ ), results next to found for Bjorkman lignin of spruce wood (61/100 PPU). ${ }^{33}$ For the lignins extractive-free by TAPPI T280 pm-99, it was found an alkyl- $O$-aryl content less than the standard lignins (average of $51.05 \pm 1.82 / 100$ PPU). This can be correlated to possible contaminants in these lignins, as previously discussed.

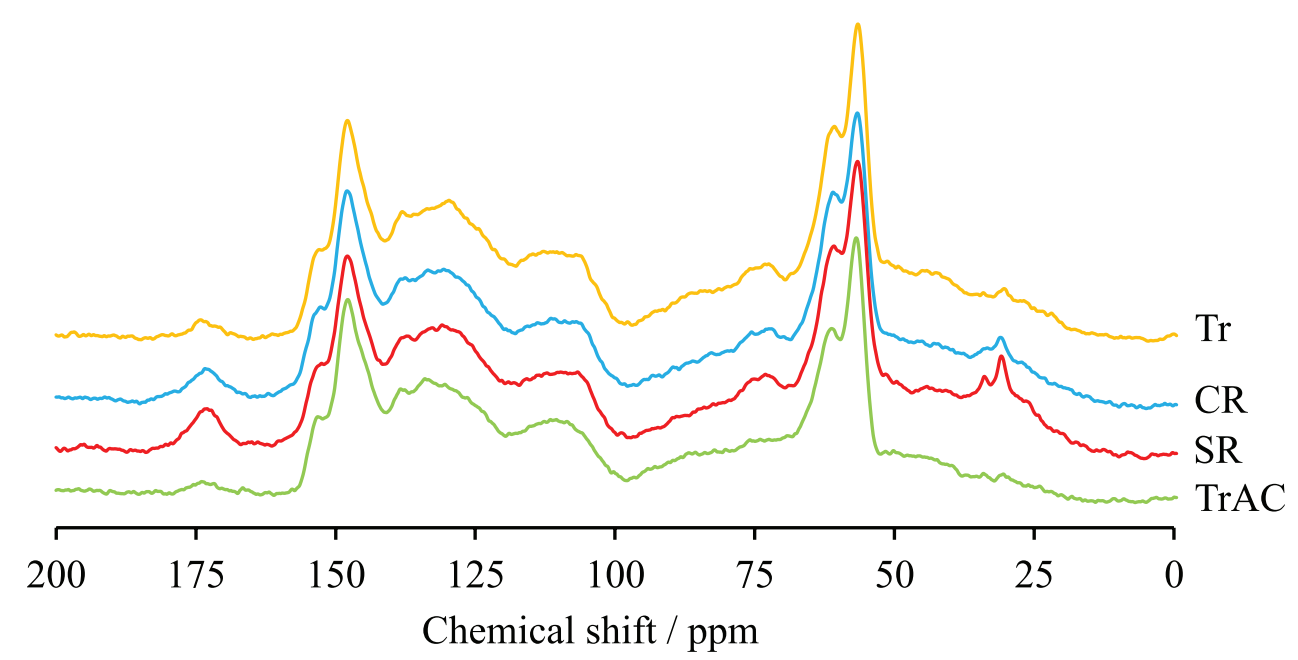

Figure 5. Solid-state ${ }^{13} \mathrm{C}$ MAS NMR (100 MHz) spectra for lignins of the trunk (Tr), central (CR), and secondary (SR) roots extractive-free by TAPPI T264 cm-97 method, and of the trunk (TrAC) extractive-free by TAPPI T280 pm-99 method. 
The methoxyl groups content found for the different lignins presented a correlation similar to that found for the alkyl-O-aryl content, but an OMe content for lignins extractive-free by TAPPI T264 cm-97 $(16.64 \pm 0.48 \%)$ greater than for lignins extractive-free by TAPPI T280 pm-99 (16.07 $\pm 0.65 \%)$. The lignin from orange tree presented similar methoxyl groups content to the described for Bjorkman lignin of spruce wood $(15.8 / 100 \text { PPU })^{33}$

\section{Thermal features}

\section{Differential scanning calorimetry}

The glass transition regions in the DSC curves for the lignin extractive-free samples are shown in Figure 6 for TAPPI T264 cm-97 and TAPPI T280 pm-99 methods. The DSC curves are shown in Figure S3 (SI section).

The DSC curves for lignins extractive-free by TAPPI T264 cm-97 showed high and moderate glass transition temperature with an average value of $156^{\circ} \mathrm{C}$. It was observed the similarity between the glass transition temperatures $(\mathrm{Tg})$ to the reported values in the literature ${ }^{54}$ for lignin, from 90 to $180^{\circ} \mathrm{C}$. The high rigidity and complexity of bonds among the monomers of the biopolymer lead to the moderate glass transition temperature explaining the values observed in the analyses. This occurs differently in simple olefin polymers, for example, which has a simple chain and lower molecular weight. ${ }^{55}$ The presence of large lateral groups allows cross-link in different parts of the macromolecule chain, requiring more energy to acquire mobility (which is the point of the glass transition) with the possible lignin recondensation in acid medium. Moreover, lignins do not have a linear backbone with fixed angles among carbon atoms. These characteristics may explain the behavior of lignin in relation to its solubility since the solid presents cross-linked chains containing few regions for possible interaction with the solvent. ${ }^{55}$ According to

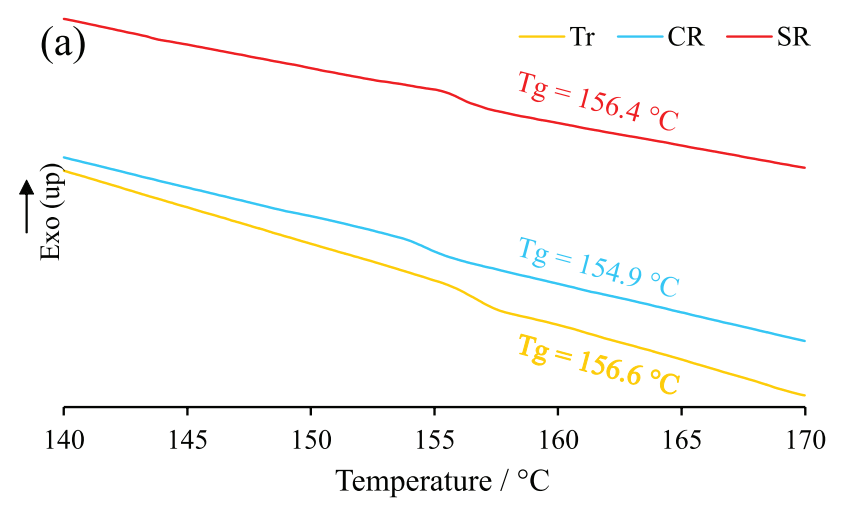

de Oliveira et al. ${ }^{22}$ the condensations in the lignin structure are mainly related to the $5-5, \beta-5$, and $\beta-1$ bonds between phenylpropanoid units, which can be formed during acid hydrolysis.

Similar aspects were found for all DSC curves for lignin samples, regardless of the organ of the orange tree or extraction method applied in this work. However, the DSC curves for lignin samples extractive-free by TAPPI T280 pm-99 showed a glass transition temperature average of $151.1{ }^{\circ} \mathrm{C}$, fewer than the value observed to the lignin samples extractive-free by TAPPI T264 cm-97 method. The high transition value can also be explained by the complexity of the lignin structure (with cross-linked bonds) and the possible lignin recondensation in acid medium, as approached for the samples extractive-free by TAPPI T264 cm-97.55

\section{Thermogravimetric analysis}

The derivative thermogravimetry (DTG) curves for the several lignin samples showed a wide temperature range of thermal decomposition, presenting in the most samples two regions with loss of weight: the first occurred at temperatures ranging between 25 and $110{ }^{\circ} \mathrm{C}$ and the second one from 220 to $560{ }^{\circ} \mathrm{C}$. The $\mathrm{T}_{\max }$, the temperature at which the thermal degradation rate is maximum, found in the DTG curves for lignins of the trunk, central and secondary roots, extractive-free by the TAPPI T264 cm-97, and TAPPI T280 pm-99 methods are shown in Table 5. The DTG curves are shown in Figure S4 (SI section).

The DTG of all extractive-free lignin samples extractive-free by TAPPI T264 cm-97 were similar among themselves showing a pyrolysis mechanism. The first thermal decomposition temperature was observed in $\mathrm{T}_{\max }$ of $61{ }^{\circ} \mathrm{C}$ (average). This event was correlated to the loss of residues, such as solvents and other volatile compounds. The second thermal decomposition, in the $\mathrm{T}_{\max }$ average of $393.8{ }^{\circ} \mathrm{C}$, could be attributed to the lignin pyrolysis.

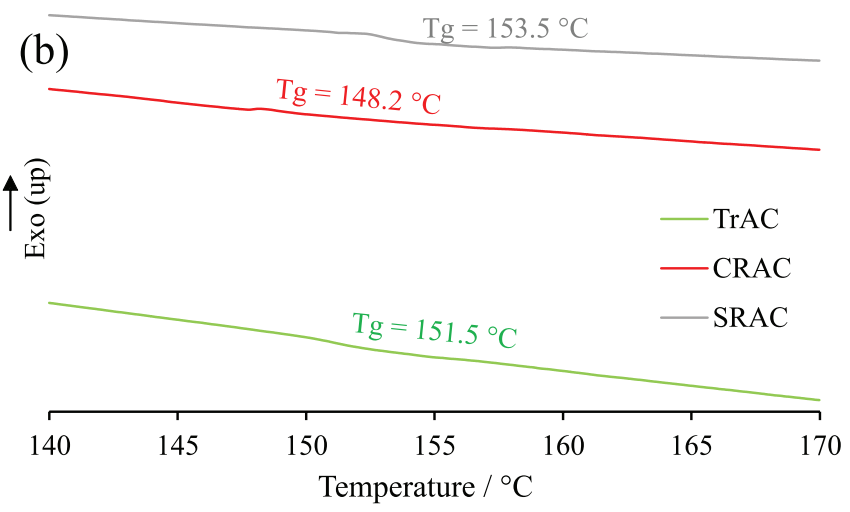

Figure 6. Region of the glass transition in the DSC curves for lignins of the secondary and central roots, and trunk extractive-free by (a) TAPPI T264 cm-97 and (b) TAPPI T280 pm-99 methods. 
Table 5. Regions found for lignins DTG of the trunk, central and secondary roots from the orange tree, extractive-free by TAPPI T264 cm-97 and TAPPI T280 pm-99

\begin{tabular}{lccc}
\hline \multirow{2}{*}{ Sample } & \multicolumn{3}{c}{$\mathrm{T}_{\text {max }} /{ }^{\circ} \mathrm{C}$} \\
\cline { 2 - 4 } & $\begin{array}{c}1^{\text {st }} \text { event } \\
\left(25-110^{\circ} \mathrm{C}\right)\end{array}$ & $\begin{array}{c}2^{\text {nd }} \text { event } \\
\left(220-550{ }^{\circ} \mathrm{C}\right)\end{array}$ & $\begin{array}{c}3^{\text {rd }} \text { event } \\
\left(550-790{ }^{\circ} \mathrm{C}\right)\end{array}$ \\
\hline Trunk $^{\mathrm{a}}$ & 57.2 & 396.3 & - \\
Central root $^{\mathrm{a}}$ & 62.3 & 394.5 & - \\
Secondary root $^{\mathrm{a}}$ & 63.3 & 390.6 & - \\
Trunk $^{\mathrm{b}}$ & 54.3 & 356.9 & 664.1 \\
Central root $^{\mathrm{b}}$ & 55.1 & 392.8 & - \\
Secondary root $^{\mathrm{b}}$ & 51.6 & 394.4 & - \\
\hline
\end{tabular}

${ }^{a}$ Extractive-free by TAPPI T264 cm-97; bextractive-free by TAPPI T280 pm-99. $\mathrm{T}_{\max }$ : maximum temperature.

Several processes related to thermal degradation for this macromolecule starts at $300{ }^{\circ} \mathrm{C}$, by a breakdown of lignin inter-units resulting in the loss of phenolic structures, and even the aromatic rings degradation. ${ }^{56}$

The DTG curves of lignin samples extractive-free by TAPPI T280 pm-99 method of central and secondary roots were very similar. These samples showed the first and second average thermal decomposition temperature at $\mathrm{T}_{\max }$ of 53.7 and $393.8^{\circ} \mathrm{C}$, respectively. Similarly, as observed in the extractive-free samples by TAPPI T264 cm-97 method, these events were connected to the loss of residues and the degradation of lignin inter-units, respectively.

The lignins of the trunk presented the second thermal degradation at $\mathrm{T}_{\text {max }}$ of $356.9^{\circ} \mathrm{C}$, relative to degradation of the lignin inter-units, and a third event at $\mathrm{T}_{\max }$ of $664.1^{\circ} \mathrm{C}$, probably due to thermal degradation of modified lignins with sulfur resulted from acid hydrolysis by $\mathrm{H}_{2} \mathrm{SO}_{4} \cdot{ }^{56}$

\section{Conclusions}

Lignins of the trunk and roots from the orange tree were extracted, quantified, and analyzed using the TAPPI standard methods. The orange tree showed approximately $20 \%(\mathrm{~m} / \mathrm{m})$ of lignin. The results were consistent with the quantity of lignin previously reported to branches of orange trees, and hardwood roots. The largest quantity of lignin among trunk and roots was found in the central root $(21.9 \%)$, the part responsible for the tree support. The central root, one of the least interest biomasses in the industry, showed be itself a raw material of great interest for lignin production, attractive economically due to the lignin content, its low cost, and availability. The extractive method with acetone/water (TAPPI T280 pm-99) can be used for lignin qualitative analysis due to its lignin content close to the standard method, in addition to the use of solvents more environmentally friendly than TAPPI T264 cm-97. IR and ${ }^{13} \mathrm{C}$ NMR analyses confirmed typical bands and chemical shifts to syringyl $\left(1,326\right.$ and $\left.1,115 \mathrm{~cm}^{-1} ; \delta_{\mathrm{C}} 153 \mathrm{ppm}\right)$ and guaiacyl $\left(1,267\right.$ and $\left.1,220 \mathrm{~cm}^{-1} ; \delta_{\mathrm{C}} 110-120 \mathrm{ppm}\right)$ units. The OMe content (ca. 16\%), S/G ratio (ca. 1), NMR spectra, and $\mathrm{Tg}$ (ca. $156^{\circ} \mathrm{C}$ ) for the different lignins extractive-free by the standard method were similar, indicating that the lignins in the trunk and roots have the same chemical and thermal features. The evaluation of lignin and its composition in Citrus sinensis were performed due to the absence of data in the literature for roots and trunks for that species. This study starts up a new range of possibilities for the biomass from the orange tree, adding value to a widely disposed material. The paper is an important part of the study involving the orange lignin and its use to obtain nanoparticles loaded with biopesticide, using lignins as a biopolymer.

\section{Supplementary Information}

Supplementary data (elemental composition, FTIR and NMR spectra, DSC, and DTG curves) associated with this article is available free of charge at http://jbcs.sbq.org.br as PDF file.

\section{Acknowledgments}

This research work was supported in part by the National Council for Scientific and Technological Development (CNPq, 133635/2015-5; 403302/2013-7; 429404/2018-2), and São Paulo Research Foundation (FAPESP, 2011/00970-4; 2011/11860-5).

\section{References}

1. Meyer, J. R.; Waghmode, S. B.; He, J.; Gao, Y.; Hoole, D.; Sousa, L. C.; Balan, V.; Foston, M. B.; Biomass Bioenergy 2018, 119, 446.

2. Lin, L. S. C.; Pfaltzgraff, L. A.; Herrero-Davila, L.; Mubofu, E. B.; Abderrahim, S.; Clark, J. H.; Koutinas, A. A.; Kopsahelis, N.; Stamatelatou, K.; Dickson, F.; Thankappan, S.; Mohamed, Z.; Brocklesby, R.; Luque, R.; Energy Environ. Sci. 2013, 6, 426.

3. Yamakawa, C. K.; Qin, F.; Mussatto, S. I.; Biomass Bioenergy 2018, 119, 54.

4. Pfaltzgraff, L. A.; De bruyin, M.; Cooper, E. C.; Budarin, V.; Clark, J. H.; Green Chem. 2013, 15, 307.

5. Parada, M. P.; Osseweijer, P.; Duque, J. A. P.; Ind. Crops Prod. 2017, 106, 105.

6. Cherubini, F.; Energy Convers. Manage. 2010, 51, 1412.

7. Alisaraei, A. T.; Motevali, A.; Renewable Sustainable Energy Rev. 2017, 69, 1100. 
8. Rauf, A.; Uddin, G.; Ali, J.; Org. Med. Chem. Lett. 2014, 4, 5.

9. Zema, D. A.; Calabrò, P. S.; Folino, A.; Tamburino, V.; Zappia, G.; Zimbone, S. M.; Waste Manage. 2018, 80, 252.

10. https://apps.fas.usda.gov/psdonline/circulars/citrus.pdf, accessed in July 2020.

11. http://www.cnpmf.embrapa.br/Base_de_Dados/index_pdf/ dados/brasil/laranja/b1_laranja.pdf, accessed in July 2020.

12. ht t p s://www.fundecitrus . com.br/pdf/pes _ relatorios/2020_05_11_Executive-Summary-of-Orange-CropForecast-for-the-2020-2021-Season.pdf, accessed in July 2020.

13. Moreira, P. H. S. S.; Cezar, J.; Freitas, D. O.; Martins, R.; Mendonça, R.; Angelo, M.; de Souza, F.; Ind. Crops Prod. 2018, 116, 144.

14. Lacerda, T. M.; Zambon, M. D.; Frollini, E.; Ind. Crops Prod. 2015, 71, 163.

15. Mvumi, B. M.; Gwenzi, W.; Mhandu, M. G.; Ind. Crops Prod. 2017, 110, 123.

16. Magalhães Jr., A. I.; de Carvalho, J. C.; Pereira, G. V. M.; Karp, S. G.; Câmara, M. C.; Medina, J. D. C.; Soccol, C. R.; Biofuels, Bioprod. Biorefin. 2019, 13, 1505.

17. Moral, A.; Tijero, A.; Aguado, R.; Mutj, P.; J. Cleaner Prod. 2016, 112, 980.

18. Arami, M.; Yousefi, N.; Mohammad, N.; J. Colloid Interface Sci. 2005, 288, 371.

19. Matharu, A. S.; de Melo, E. M.; Houghton, J. A.; Bioresour. Technol. 2016, 215, 123.

20. Saliba, E. O. S.; Rodriguez, N. M.; de Morais, S. A. L.; Piló-Veloso, D.; Cienc. Rural 2001, 31, 917.

21. Pinheiro, F. C. G.; Kelly, A.; Soares, L.; Tédde, S.; Mara, L.; Marques, K.; Alberto, C.; de Freitas, M.; Pessoa, J.; Feitosa, D. A.; Carrhá, R.; Ind. Crops Prod. 2017, 96, 80.

22. de Oliveira, F.; Gomes, C.; Ramos, L. A.; Frollini, E.; Ind. Crops Prod. 2017, 96, 30.

23. Faustino, H.; Gil, N.; Baptista, C.; Duarte, A. P.; Molecules 2010, 15, 9308.

24. Belgacem, M. N.; Gandini, A.; Monomers, Polymers and Composites, $1^{\text {st }}$ ed.; Elsevier: Chennai, India, 2008.

25. Clark, J. H.; Budarin, V.; Deswarte, F. E. I.; Hardy, J. J. E.; Kerton, F. M.; Hunt, A. J.; Luque, R.; Macquarrie, D. J.; Milkowski, K.; Rodriguez, A.; Samuel, O.; Tavener, S. J.; White, R. J.; Wilson, A. J.; Green Chem. 2006, 8, 853.

26. Nicholson, D. J.; Leavitt, A. T.; Francis, R. C.; Cellul. Chem. Technol. 2014, 48, 53.

27. TAPPI T222 om-02: Acid-Insoluble Lignin in Wood and Pulp; Technical Association of the Pulp and Paper Industry (TAPPI): Atlanta, GA, USA, 2002, available at https://www.techstreet. com/standards/tappi-t-222?product_id=921199\#jumps, accessed in July 2020.

28. TAPPIT264 cm-97: Preparation of Wood for Chemical Analysis; Technical Association of the Pulp and Paper Industry (TAPPI): Atlanta, GA, USA, 1997, available at https://www.techstreet. com/standards/tappi-t264-cm-97?product_id=921224, accessed in July 2020.

29. TAPPI T280 pm-99: Acetone Extractives of Wood and Pulp; Technical Association of the Pulp and Paper Industry (TAPPI): Atlanta, GA, USA, 1999, available at https://www.techstreet. com/standards/tappi-t280-pm-99?product_id=921238, accessed in July 2020.

30. ISO 3451-1:2008: Plastics - Determination of Ash Part 1: General Methods; International Organization for Standardization (ISO): Vernier, Geneva, Switzerland, 2008, available at https://www.iso.org/standard/41663.html, accessed in July 2020.

31. https://www.infoteca.cnptia.embrapa.br/bitstream/ doc/883400/1/DOC236.pdf, accessed in July 2020.

32. Kline, L. M.; Hayes, D. G.; Womac, A. R.; Labbé, N.; BioResources 2010, 5, 1366.

33. Evstigneyev, E. I.; Mazur, A. S.; Kalugina, A. V.; Pranovich, A. V.; Vasilyev, A. V.; J. Wood Chem. Technol. 2018, 38, 137.

34. Meena, S. K.; Meena, V. S. In Agriculturally Important Microbes for Sustainable Agriculture, vol. 2; Meena, V. S.; Mishra, P. K.; Bisht, J. K.; Pattanayak, A., eds.; Springer Singapore: Singapore, 2017, p. 3-23.

35. Gomes, F. J. B.; Colodette, J. L.; Burnet, A.; Aparecida, L.; Batalha, R.; Santos, F. A.; Demuner, I. F.; Int. J. For. Res. 2015, 2015, 10 .

36. Pettersen, R. C. In The Chemistry of Solid Wood, $1^{\text {st }}$ ed.; Rowell, R., ed.; American Chemical Society: Washington, DC, USA, 1984, p. 57-126.

37. Rowell, R.; Pettersen, R.; Tshabalala, M. In Handbook of Wood Chemistry and Wood Composites, $2^{\text {nd }}$ ed.; Rowell, R., ed.; CRC Press: Boca Raton, FL, USA, 2012, p. 33-72.

38. Watkins, D.; Nuruddin, Md.; Hosur, M.; Tcherbi-Narteh, A.; Jeelani, S.; J. Mater. Res. Technol. 2015, 4, 26.

39. González, Z.; Rosal, A.; Requejo, A.; Rodríguez, A.; Bioresour. Technol. 2011, 102, 9330.

40. Zhang, C.; Chen, L.; Jiang, J.; Geomorphology 2014, 206, 196.

41. Novaes, E.; Kirst, M.; Chiang, V.; Winter-Sederoff, H.; Sederoff, R.; Plant Physiol. 2010, 154, 555.

42. Sameni, J.; Krigstin, S.; Sain, M.; BioResources 2017, 12, 1548.

43. Tortora, M.; Cavalieri, F.; Mosesso, P.; Ciaffardini, F.; Melone, F.; Crestini, C.; Biomacromolecules 2014, 15, 1634.

44. Ibrahim, M. N. M.; Zakaria, N.; Sipaut, C. S.; Sulaiman, O.; Hashim, R.; Carbohydr. Polym. 2011, 86, 112.

45. Costa, E. S.; Perlatti, B.; da Silva, E. M.; Matos, A. P.; da Silva, M. F. G. F.; Fernandes, J. B.; Zuin, V. G.; da Silva, C. M. P.; Forim, M. R.; J. Braz. Chem. Soc. 2017, 28, 126.

46. Rutkowska, E. W.; Wollboldt, P.; Zuckerstatter, G.; Weber, H. K.; Sixta, H.; BioResources 2009, 4, 172.

47. Pu, Y.; Hallac, B.; Ragauskas, A. In Aqueous Pretreatment of Plant Biomass and Chemical Conversion to Fuels and 
Chemicals, $1^{\text {st }}$ ed.; Wyman, C. E., ed.; JohnWiley \& Sons: West Sussex, UK, 2013, p. 369-390.

48. Fu, L.; Mccallum, S. A.; Miao, J.; Hart, C.; Tudryn, G. J.; Zhang, F.; Linhardt, R. J.; Fuel 2015, 141, 39.

49. Angelini, S.; Cerruti, P.; Immirzi, B.; Scarinzi, G.; Malinconico, M.; Eur. Polym. J. 2016, 76, 63.

50. Bernardinelli, O. D.; Lima, M. A.; Rezende, C. A.; Polikarpov, I.; deAzevedo, E. R.; Biotechnol. Biofuels 2015, 8, 110.

51. Holtman, K. M.; Chen, N.; Chappell, M. A.; Kadla, J. F.; Ling, X.; Mao, J.; J. Agric. Food Chem. 2010, 58, 9882.

52. El Hage, R.; Brosse, N.; Chrusciel, L.; Sanchez, C.; Sannigrahi, P.; Ragauskas, A.; Polym. Degrad. Stab. 2009, 94, 1632.
53. Martínez, A. T.; Frund, R.; Solid State Nucl. Magn. Reson. 1999, $15,41$.

54. Gordobil, O.; Moriana, R.; Zhang, L.; Labidi, J.; Sevastyanova, O.; Ind. Crops Prod. 2016, 83, 155.

55. Canevarolo, S. V.; Ciência dos Polímeros, $2^{\text {nd }}$ ed.; Artliber Editora: São Paulo, SP, Brazil, 2006.

56. Ashter, S. A.; Technology and Applications of Polymers Derived from Biomass, $1^{\text {st }}$ ed.; Elsevier Inc.: Lowell, Massachusetts, USA, 2018.

Submitted: April 12, 2020

Published online: July 24, 2020 